\title{
IMMUNOCHISTOCHEMICAL CHARACTERISTICS OF BLOOD VESSELS IN NON-VISUALIZED AND VISUALIZED ON MRI PITUITARY ADENOMAS IN PATIENTS WITH CUSHING'S DISEASE (PILOT STUDY)
}

Belaya ZE, Voronkova IA, Khandaeva PM, Rozhinskaya LYa, Vorontsov AV, Sitkin II, Grigoriev AU, Melnichenko GA

Regardless of improvements in MRI, up to $20 \%$ of ACTH-secreting pituitary tumors are only identified at surgical exploration. The objective was to estimate whether there is any difference in blood vessels and the subsequent ability to uptake contrast agent in visualized micro-adenomas as compared to non-visualized on MRI ACTH-secreting pituitary tumors.

\section{Material and methods:}

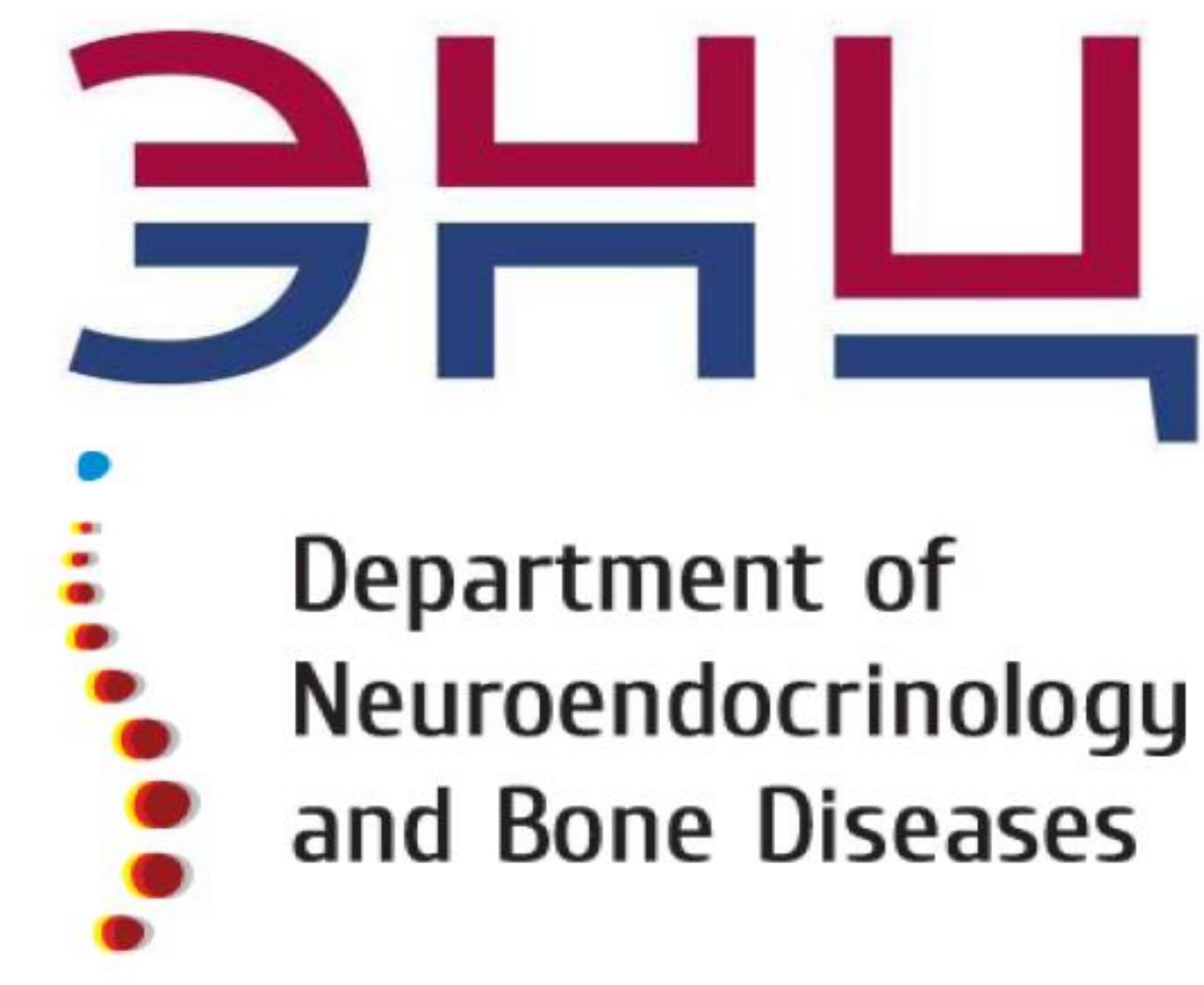

Retrospective evaluation of ACTH-positive pituitary tumors from patients with Cushing's disease ( $n=24)$ with either non-visualized pituitary tumor on MRI $(n=7)$ or pituitary tumor less then $10 \mathrm{~mm}(n=17)$. Cushing's disease was confirmed by histological evaluation in all enrolled subjects. Selected tumors were treated immunohistochemically with antibodies to the following antigens: CD34 (clone QBEnd/10, RTU, Leica) or CD 31(clone 1A10, RTU, Leica), D2-40 (clone D2-40, RTU, Dako). A biotin-free Bond Polymer Refine Detection system (Leica) was used according to standard protocols with the automated system Bond max (Leica).The investigators were not aware of the diagnosis before performing the micro vessel counting. The representative field $\times 200$ magnifications were chosen for each tumor. These fields were digitized as JPEG images using a digital camera system (Leica, DFC 490). Image-processing software (Leica Application suite V3). We calculated the density of micro vessels and measured the diameter of larger and smaller vessel.

\section{Results:}

The density of blood vessels were not different in subject with visualized Me-112 (Q25-Q75 95-136) and non-visualized 117 (56-138) pituitary adenomas. However the shape and diameter of these vessels differ: the largest of visible vessels tend to be larger in patients with non-visualized pituitary adenomas 65 (41-93) vs 35 (25-66) $\mathrm{p}=0.06$; the diameter of medium vessels were significantly higher in subjects with non-visualized adenoma $16.0(13.5-30.0)$ vs $12.5(11.7-14.2) p=0.028$, the diameter of small vessels were not different 7.0 (5.0-9.5) vs 7.0 (6.0-9.3). In 6 cases the vessels were slit-shaped and 5 of these cases were patients with visualized pituitary adenomas on MRI.

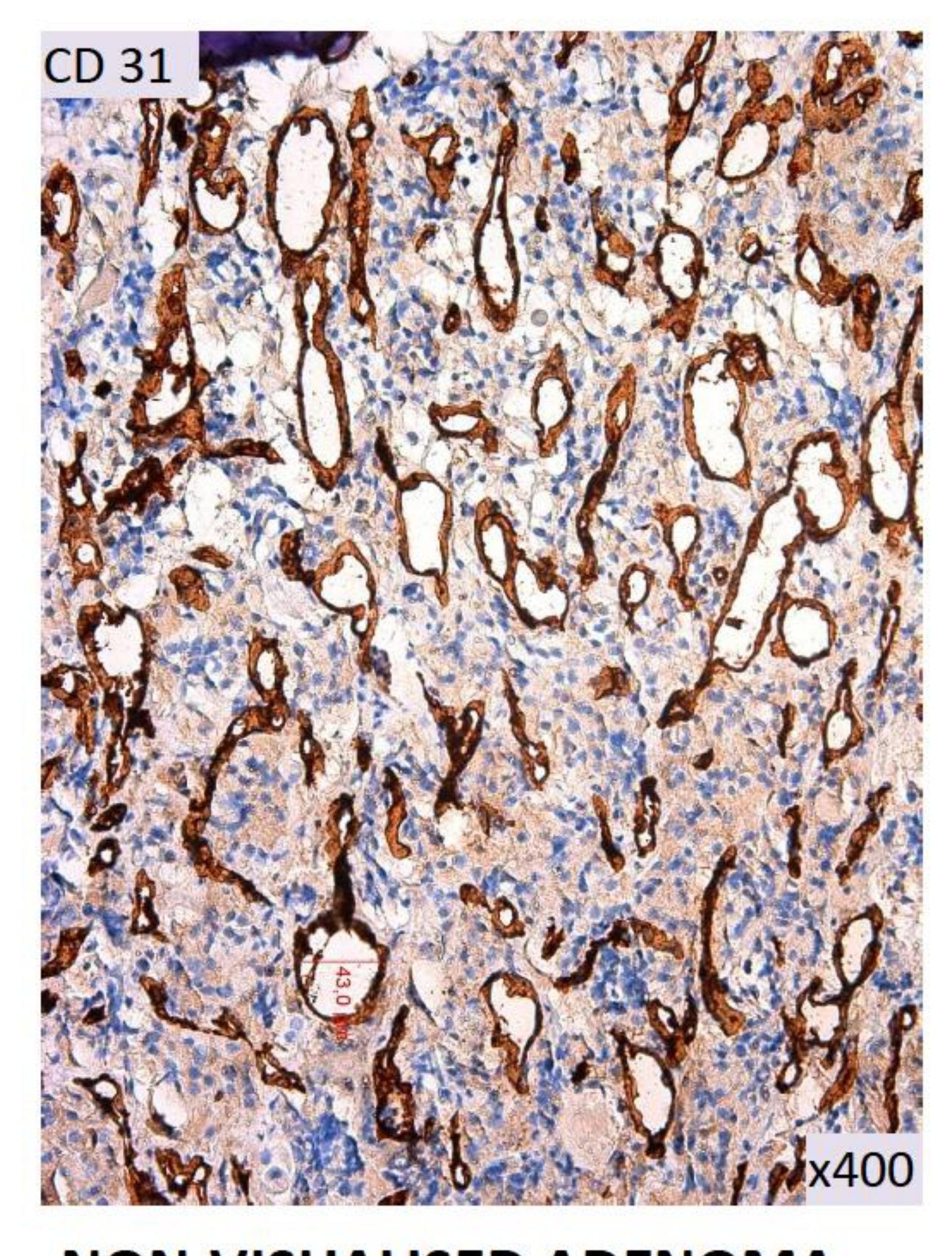

NON-VISUALISED ADENOMA

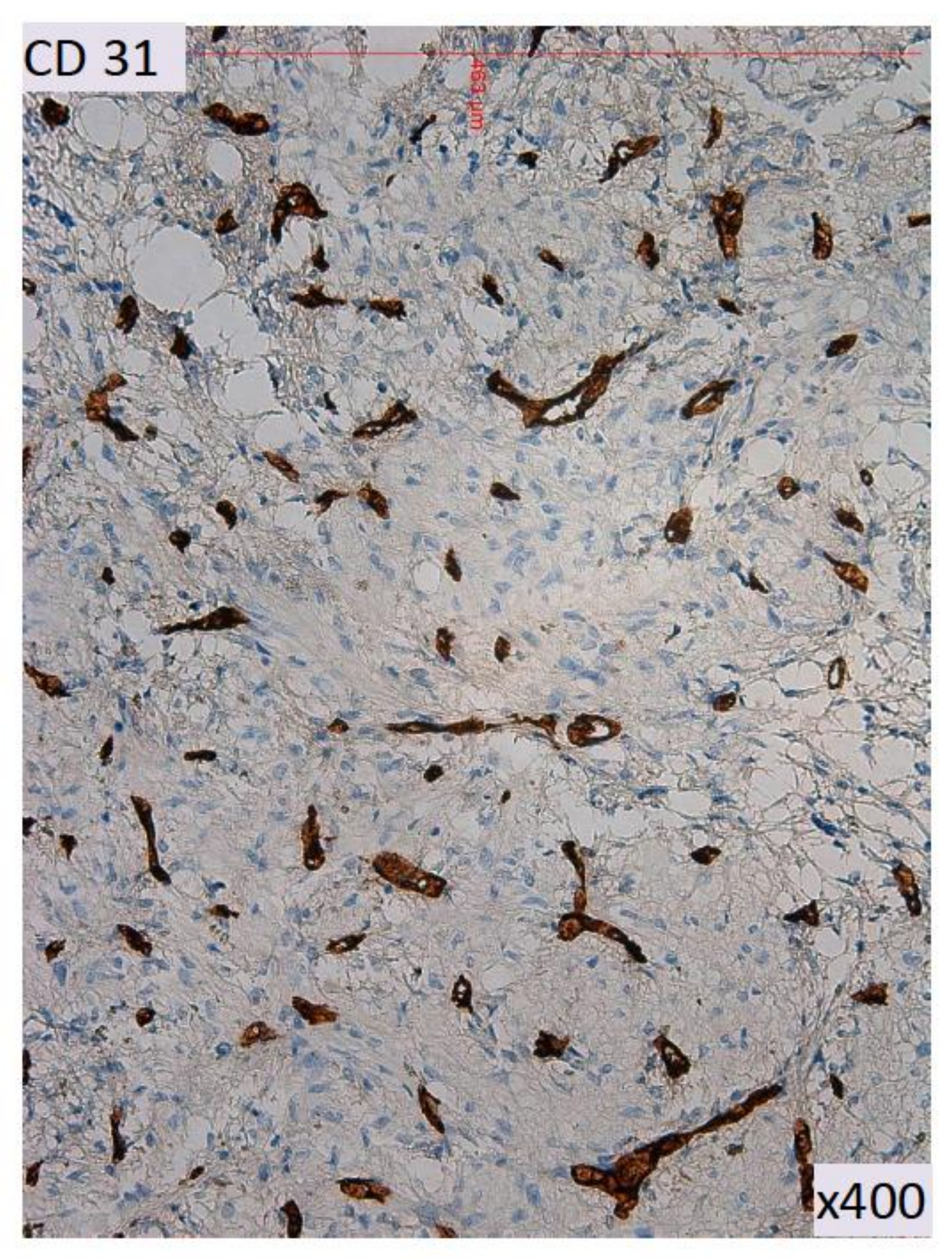

VISUALISED ADENOMA
BASELINE CHARACTERISTICS OF PARTICIPANTS

\begin{tabular}{|c|c|c|c|}
\hline CHARACTERISTIC & $\begin{array}{l}\text { WITHOUT } \\
\text { VISUALIZED } \\
\text { ADENOMA }\end{array}$ & $\begin{array}{l}\text { WITH VISUALIZED } \\
\text { ADENOMA }\end{array}$ & $\mathbf{P}$ \\
\hline & \multicolumn{2}{|c|}{ Mean (95\% confidence interval) } & \\
\hline Age & $34(16-53)$ & $35(20-51)$ & 0.096 \\
\hline Sex M (\%):F (\%) & $\begin{array}{l}5(60.0 \%): \\
2(40.0 \%)\end{array}$ & $\begin{array}{c}\text { 15(86.7\%): } \\
2(13.3 \%)\end{array}$ & 0.594 \\
\hline $\begin{array}{c}\text { density of blood } \\
\text { vessels }\end{array}$ & $117(56-138)$ & 112(95-136) & 0.41 \\
\hline $\begin{array}{l}\text { The diameter of } \\
\text { the large vessels }\end{array}$ & $65(41-93)$ & $35(25-66)$ & 0.06 \\
\hline $\begin{array}{l}\text { The diameter of } \\
\text { the medium } \\
\text { vessels }\end{array}$ & $16,0(13,5-30,0)$ & $12,5(11,7-14,2)$ & 0.028 \\
\hline
\end{tabular}

The diameter of the small vessels

$7,0(5,0-9,5) \quad 7,0(6,0-9,3)$

0,995

slit-shaped vessels

1

5

0,629

CONCLUSION: The larger diameter of blood vessels in subjects with non-visualized pituitary adenomas might influence the contrast agent uptake and its retention making the pituitary adenoma tissue less different from normal pituitary. 